\title{
Machining Characteristics and Parametric Optimisation of Inconel 825 during Electric Discharge Machining
}

\author{
Himanshu PAYAL, Pushpendra S. BHARTI, Sachin MAHESHWARI, Divya AGARWAL
}

\begin{abstract}
This paper presents the machining characteristics and parametric optimisation of Inconel 825 during die-sinking electrical discharge machining (EDM) process This work considers seven input parameters out of which six are of three levels and one is of one level. Metal removal rate (MRR), tool wear rate (TWR) and surface roughness $(S R)$ have been considered as performance measures. Before carrying out physical experimental runs, the experiments have been designed using Taguchi's $L 36$ $\left(2^{1} \times 3^{6}\right)$ orthogonal array $(\mathrm{OA})$. In order to identify the significant input parameters, Analysis of Variance has been employed on the experimental data. Discharge current, pulse-on-time, tool material and tool electrode lift time are found as significant input parameters. The effects of these significant parameters on the performance measures have been presented using Taguchi's technique. After machining, study of surface characteristics of the electric discharged machined surface has been carried out using scanning electron microscopy (SEM), energy dispersive x-ray spectroscopy (EDXS) and X-ray diffraction (XRD). These studies help in obtaining the information pertaining to topography of the machined surface, material transfer from tool and dielectric to the machined surface, and presence of extra element and their different phases at the machined surface. It has been found from the research that Carbon, Oxygen, Iron, Nickel, Chromium and little amount of Molybdenum are transferred to the surface of work piece. Further, for the best yield of the process, the optimal combination of input parameters has been obtained and reported using Technique for Order of Preference by Similarity to Ideal Solution (TOPSIS) as a multi-objective optimisation technique. Consideration of two different dielectric fluids and three different electrode materials is the novelty of the work
\end{abstract}

Keywords: EDM; EDXS; optimisation; SEM; TOPSIS; XRD

\section{INTRODUCTION}

Inconel 825, a nickel-based super alloy, finds wide applications in the field of aerospace, marine, furnace components, orthopaedic etc. $[1,2]$. The intrinsic properties like work hardening, poor thermal diffusivity and high dynamic shear strength makes it difficult to be machined on conventional machines. EDM, a nonconventional machining process, is suitable to shape this alloy. EDM is a thermo-electric process in which material removal takes place due to electric discharge erosion effect of electric sparks between the tool electrode and work piece (both submerged in a dielectric medium) that are separated at a particular distance [3, 4].

However, much work has been reported in literature regarding EDM of super alloys like Inconel 718 [5-7] SuperCo605 [8], Ni-based alloy [9], Inconel 800 [10], Nimonic 75 [11] and Monel $400[12,13]$, there is scanty of data in respect of EDM of Inconel 825. Rahul et al. [14] studied the surface integrity and metallurgical characteristics of Inconel 825 using cryogenically treated tool and non- treated tool. They emphasized on the surface cracking and white layer formation at the machined work piece. Kumar et al. [15] proposed a low cost $\mathrm{Al}_{2} \mathrm{O}_{3}$ nano powder for the machining of Inconel 825 material. They used nano powder of size 45 to $50 \mathrm{~nm} \mathrm{Al}_{2} \mathrm{O}_{3}$ mixed with deionized water (dielectric) to improve surface characteristics. Mohanty et al. [16] presented the effects of various input parameters on performance measures like MRR, SR, radial overcut (ROC) and surface crack density (SCD). They employed Taguchi $L 9$ OA for experimental design. Prabhu \& Vinayagam [17] studied the effect of multiwall carbon nano (CNT) tube mixed in the dielectric fluid in EDM of Inconel 825. The experiments were planned using Taguchi's Design of experiment (DOE) to get the optimal machining parameters.

Prabhu \& Vinayagam [18] presented the importance of single wall CNT mixed with dielectric fluid to analyse the surface characteristics of Inconel 825. It was found from the experimental results that surface texture is better after EDM due to discharge energy. This work presents experimental investigations during EDM of Inconel 825. During literature review, authors could not come across some work which considers three levels of electrode material and two levels of dielectric fluid for experimental investigations during EDM of Inconel 825. In this work dielectric fluid $\left(D_{\mathrm{F}}\right)$, pulse-on-time $\left(T_{\mathrm{on}}\right)$, discharge current $\left(I_{\mathrm{D}}\right)$, duty cycle $(\zeta)$, gap voltage $\left(V_{\mathrm{g}}\right)$, tool electrode lift time $\left(T_{\mathrm{L}}\right)$ and tool electrode material $\left(T_{\mathrm{M}}\right)$ are taken as process parameters and $M R R, S R$ and $T W R$ are taken as performance measures.

Besides this, surface characterization and topography of the machined surface have also been carried out by SEM analysis. To ascertain the transfer of material from the tool and dielectric to the machines surface, EDXS has been performed. Further, XRD analysis has also been carried out for finding the presence of extra elements and their different phases. The novelty of this work is consideration of two levels of dielectric fluid and three levels of electrode materials: copper $(\mathrm{Cu})$, graphite $(\mathrm{Gr})$ and copper-tungsten (Cu 20\%; W 80\%).

The selection of optimal combination of input parameters, for the best machining performance, is an important and challenging task in the field of EDM. EDM is a very complex machining process due to involvement of many electric and non-electric parameters. More so, it becomes a multi-objective optimisation task owing to conflicting nature of performance measures. Higher MRR is desired along with lower SR and TWR. Several researchers have employed different multi-objective optimisation techniques for the parametric optimisation e.g. genetic algorithm, simulated annealing, particle swam optimisation, grey relation analysis [19-23]. This work employs TOPSIS method as multi-objective optimisation technique to find the optimal combination of input parameters. Some authors have employed this technique in the field of EDM for different materials [24], the authors could not come across some work that employs this 
technique for Inconel 825. In EDM, $M R R$ and $S R$ are primarily two main concerns in respect of performance improvement. Hence, in this work, optimisation has been done by considering two performance measures i.e. $M R R$ and $S R$. The third performance measure $(T W R)$ has not been considered for optimisation.

\section{MATERIALS AND METHOD}

Mechanical properties and chemical composition of Inconel 825 are given in Tab. 1 and Tab. 2. The input parameters and their levels are shown in Tab. 3.

Table 1 Mechanical properties of Inconel 825

\begin{tabular}{|l|c|c|}
\hline \multicolumn{1}{|c|}{ Property } & Value & Units \\
\hline Density & 8.14 & $\mathrm{~g} / \mathrm{cm}^{3}$ \\
\hline Melting Point & 1400 & ${ }^{\circ} \mathrm{C}$ \\
\hline Hardness & $89-90$ & $\mathrm{HRB}$ \\
\hline Coefficient of expansion & 14 & $\mathrm{~m} / \mathrm{m} /{ }^{\circ} \mathrm{C}$ \\
\hline Modulus of elasticity & 196 & $\mathrm{kN} / \mathrm{mm}^{2}$ \\
\hline Modulus of rigidity & 75.9 & $\mathrm{~N} / \mathrm{mm}^{2}$ \\
\hline
\end{tabular}

Table 2 The Chemical Composition of Inconel 825 Protocol IS 228/OES/XRF/Spectrometer

\begin{tabular}{|c|c|c|c|c|c|}
\hline Elements & $\mathrm{C}$ & $\mathrm{Si}$ & $\mathrm{Mn}$ & $\mathrm{S}$ & $\mathrm{P}$ \\
\hline wt. $\%$ & 0.04 & 0.10 & 0.44 & 0.010 & 0.012 \\
\hline Elements & $\mathrm{Ni}$ & $\mathrm{Cr}$ & $\mathrm{Mo}$ & $\mathrm{Cu}$ & $\mathrm{Nb}$ \\
\hline wt. $/ \%$ & 43.3 & 22.0 & 3.34 & 1.87 & 0.048 \\
\hline Elements & $\mathrm{Ti}$ & $\mathrm{V}$ & $\mathrm{Co}$ & $\mathrm{Al}$ & $\mathrm{Fe}$ \\
\hline wt. $\%$ & 0.98 & 0.036 & 0.221 & 0.07 & 27.53 \\
\hline
\end{tabular}

Table 3 Machining Parameters and their levels

\begin{tabular}{|l|c|c|c|c|c|}
\hline \multirow{2}{*}{\multicolumn{1}{c}{ Input Parameters }} & \multirow{2}{*}{ Unit } & \multirow{2}{*}{ Symbol } & \multicolumn{3}{c|}{ Levels and values } \\
\cline { 4 - 6 } & & & 1 & 2 & 3 \\
\hline Dielectric fluid & - & $D_{\mathrm{F}}$ & First oil & Second oil & - \\
\hline Pulse-on-time & $\mu \mathrm{s}$ & $T_{\text {on }}$ & 20 & 40 & 75 \\
\hline Discharge Current & $\mathrm{A}$ & $I_{\mathrm{d}}$ & 4 & 8 & 12 \\
\hline Duty cycle & $\%$ & $\zeta$ & 10 & 11 & 12 \\
\hline Gap voltage & $\mathrm{V}$ & $V_{\mathrm{g}}$ & 40 & 60 & 80 \\
\hline Tool Electrode Material & - & $T_{\mathrm{M}}$ & $\mathrm{Cu}$ & $\mathrm{CuW}$ & $\mathrm{Gr}$ \\
\hline Tool electrode lift time & $\mathrm{s}$ & $T_{\mathrm{L}}$ & 0.1 & 0.2 & 0.3 \\
\hline
\end{tabular}

The experiments have been designed by Taguchi's $L 36$ OA [5] as shown in Tab. 4. The Experiments were carried out on Elektra 5535 PS die-sinking EDM as shown in Fig. 1.

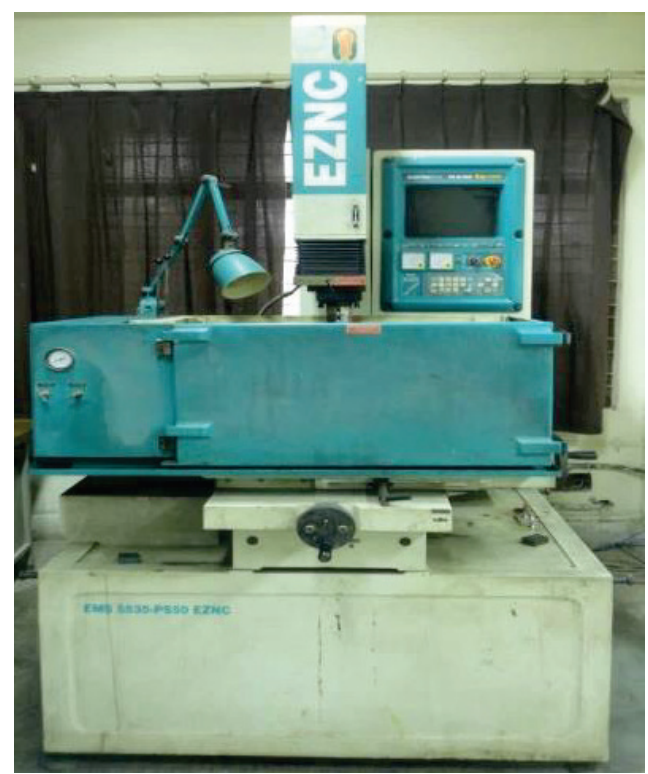

Figure 1 EDM PS50
The dielectric fluid has been taken as noise factor and two levels for the same are taken. The first dielectric fluid used for the experimentation is IPOL Spark Erosion oil SEO-250 and the second one is commercial grade EDM oil. The electrodes used in this work are electrolytic $\mathrm{Cu}$, $\mathrm{CuW}$ (Cu 20\%; W 80\%), and Gr as shown in Fig. 2.

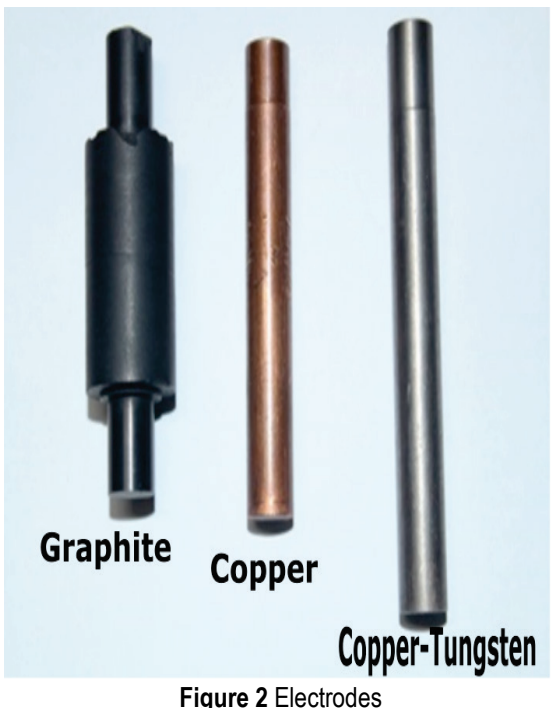

Each experimental run has been repeated thrice. The machined surface is shown in Fig. 3. For analysis of machined surface, XRD patterns have been recorded by Discover X-ray powder Diffractometer. The values which were considered using XRD spectra were $\mathrm{Cu}, \mathrm{K} \alpha$ radiations $(\lambda=1.54060 \mathrm{~A}$, the scan rate of $10 \mathrm{~min}$, range 1400 ) having a generator setting of $40 \mathrm{~mA}$ and $45 \mathrm{kV}$. Besides XRD, SEM and EDX are also done for surface morphology using SEM (JSM-6610LV Joel, Japan).

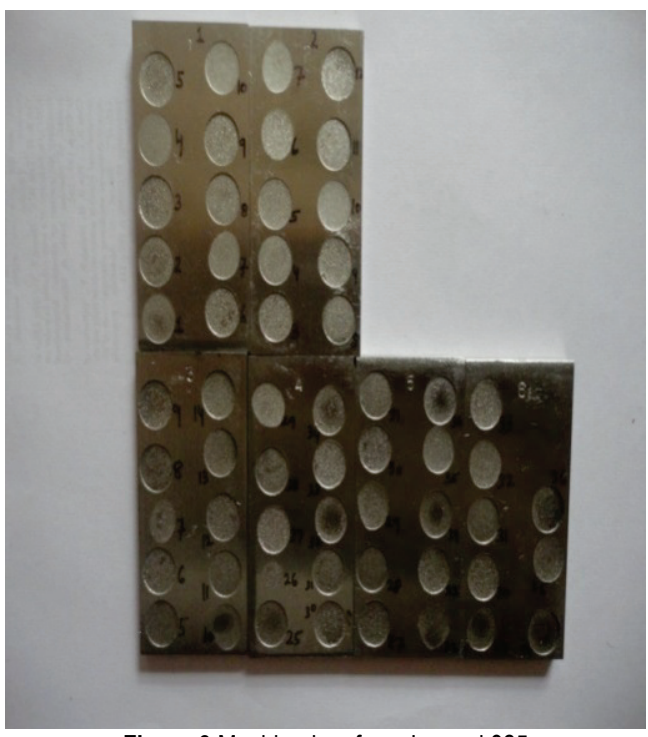

Figure 3 Machined surface Inconel 825

$M R R$ and $T W R$ can be defined as the ratio of reduction in weight of the work piece/electrode in grams divided by the density of work piece/electrode multiplied by machining time. The $M R R$ and $T W R$ are calculated by the weight loss criteria of the work piece/electrode and can be calculated by the following equation: 
$M R R$ or $T W R=$

$=$ reduction in weight of workpiece or electrode

$=\overline{\text { density of work piece or electrode } \times \text { machining time }}$

$S R$, defined as the measurement of central line average known as $(R a)$, was used to check the quality of the surface quantitatively. $S R$ has been measured by using surface Roughness Tester - MITUTOYO, JAPAN SUR-FTEST
SV-2100. The measurement was repeated three times and the average of the three readings was taken.

\section{EXPERIMENTAL RESULTS AND DISCUSSION}

The experimental values of the performance measures corresponding to all 36 experimental runs are shown in Tab. 4. The analysis of the experimental results has been done by Taguchi's method.

\begin{tabular}{|c|c|c|c|c|c|c|c|c|c|c|c|c|c|}
\hline $\begin{array}{l}\text { Exp. } \\
\text { No. }\end{array}$ & $D_{\mathrm{F}}$ & $\begin{array}{l}T_{\text {on }} \\
/ \mu \mathrm{s}\end{array}$ & $\begin{array}{l}I_{\mathrm{D}} \\
/ \mathrm{A}\end{array}$ & $\begin{array}{c}\zeta \\
1 \%\end{array}$ & $\begin{array}{l}V_{\mathrm{g}} \\
/ \mathrm{V}\end{array}$ & $T_{\mathrm{M}}$ & $\begin{array}{l}T_{\mathrm{L}} \\
/ \mathrm{S}\end{array}$ & $\begin{array}{c}M R R \\
/ \mathrm{mm}^{3} / \min \end{array}$ & $\begin{array}{c}T W R \\
/ \mathrm{mm}^{3} / \mathrm{min}\end{array}$ & $\begin{array}{c}S R \\
/ \mu \mathrm{m}\end{array}$ & $\begin{array}{c}S / N \\
M R R\end{array}$ & $\begin{array}{c}S / N \\
T W R\end{array}$ & $\begin{array}{l}S / N \\
S R\end{array}$ \\
\hline 1 & 1 & 1 & 1 & 1 & 1 & 1 & 1 & 3.0631 & 0.1264 & 4.347 & 9.7232 & 17.965 & -12.764 \\
\hline 2 & 1 & 2 & 2 & 2 & 2 & 2 & 2 & 4.8124 & 0.0611 & 6.530 & 13.647 & 24.279 & -16.298 \\
\hline 3 & 1 & 3 & 3 & 3 & 3 & 3 & 3 & 11.5162 & 1.3437 & 7.777 & 21.226 & -2.566 & -17.816 \\
\hline 4 & 1 & 1 & 1 & 1 & 1 & 2 & 2 & 2.1474 & 0.0406 & 3.864 & 6.6383 & 27.829 & -11.741 \\
\hline 5 & 1 & 2 & 2 & 2 & 2 & 3 & 3 & 4.3182 & 1.2727 & 5.789 & 12.706 & -2.094 & -15.252 \\
\hline 6 & 1 & 3 & 3 & 3 & 3 & 1 & 1 & 3.9810 & 1.1715 & 8.284 & 11.999 & -1.374 & -18.365 \\
\hline 7 & 1 & 1 & 1 & 2 & 3 & 1 & 2 & 1.1916 & 0.0643 & 5.741 & 1.5226 & 23.835 & -15.180 \\
\hline 8 & 1 & 2 & 2 & 3 & 1 & 2 & 3 & 5.0680 & 0.0616 & 6.492 & 14.096 & 24.208 & -16.248 \\
\hline 9 & 1 & 3 & 3 & 1 & 2 & 3 & 1 & 5.5072 & 2.7969 & 8.388 & 14.818 & -8.933 & -18.473 \\
\hline 10 & 1 & 1 & 1 & 3 & 2 & 1 & 3 & 2.2609 & 0.1082 & 4.544 & 7.0856 & 19.315 & -13.149 \\
\hline 11 & 1 & 2 & 2 & 1 & 3 & 2 & 1 & 3.4279 & 0.0498 & 5.916 & 10.700 & 26.055 & -15.441 \\
\hline 12 & 1 & 3 & 3 & 2 & 1 & 3 & 2 & 5.3038 & 3.3076 & 7.859 & 14.491 & -10.39 & -17.907 \\
\hline 13 & 1 & 1 & 2 & 3 & 1 & 3 & 2 & 4.4451 & 2.0977 & 4.644 & 12.957 & -6.434 & -13.338 \\
\hline 14 & 1 & 2 & 3 & 1 & 2 & 1 & 3 & 4.2817 & 1.5383 & 6.824 & 12.632 & -3.740 & -16.681 \\
\hline 15 & 1 & 3 & 1 & 2 & 3 & 2 & 1 & 1.6577 & 0.0180 & 5.844 & 4.3901 & 34.894 & -15.334 \\
\hline 16 & 1 & 1 & 2 & 3 & 2 & 1 & 1 & 3.7465 & 0.5841 & 5.287 & 11.472 & 4.6703 & -14.464 \\
\hline 17 & 1 & 2 & 3 & 1 & 3 & 2 & 2 & 5.1329 & 1.0682 & 6.872 & 14.207 & -0.573 & -16.742 \\
\hline 18 & 1 & 3 & 1 & 2 & 1 & 3 & 3 & 3.5901 & 1.2304 & 5.093 & 11.102 & -1.800 & -14.140 \\
\hline 19 & 2 & 1 & 2 & 1 & 3 & 3 & 3 & 10.4451 & 6.6839 & 4.689 & 20.378 & -16.50 & -13.422 \\
\hline 20 & 2 & 2 & 3 & 2 & 1 & 1 & 1 & 4.8870 & 1.2518 & 7.426 & 13.788 & -1.950 & -17.415 \\
\hline 21 & 2 & 3 & 1 & 3 & 2 & 2 & 2 & 1.7625 & 0.0106 & 5.605 & 4.9226 & 39.493 & -14.972 \\
\hline 22 & 2 & 1 & 2 & 2 & 3 & 3 & 1 & 3.3780 & 7.3140 & 4.991 & 10.573 & -17.28 & -13.964 \\
\hline 23 & 2 & 2 & 3 & 3 & 1 & 1 & 2 & 4.3688 & 1.2444 & 6.204 & 12.807 & -1.899 & -15.853 \\
\hline 24 & 2 & 3 & 1 & 1 & 2 & 2 & 3 & 2.4783 & 0.0291 & 6.528 & 7.8831 & 30.722 & -16.296 \\
\hline 25 & 2 & 1 & 3 & 2 & 1 & 2 & 3 & 10.0142 & 1.0751 & 5.387 & 20.012 & -0.629 & -14.627 \\
\hline 26 & 2 & 2 & 1 & 3 & 2 & 3 & 1 & 1.8366 & 1.5087 & 5.309 & 5.2803 & -3.572 & -14.500 \\
\hline 27 & 2 & 3 & 2 & 1 & 3 & 1 & 2 & 8.0770 & 0.0539 & 8.386 & 18.145 & 25.368 & -18.471 \\
\hline 28 & 2 & 1 & 3 & 2 & 2 & 2 & 1 & 5.7410 & 1.1047 & 5.488 & 15.179 & -0.864 & -14.788 \\
\hline 29 & 2 & 2 & 1 & 3 & 3 & 3 & 2 & 2.4439 & 2.8542 & 5.192 & 7.7617 & -9.109 & -14.307 \\
\hline 30 & 2 & 3 & 2 & 1 & 1 & 1 & 3 & 4.7907 & 0.0636 & 7.432 & 13.608 & 23.930 & -17.422 \\
\hline 31 & 2 & 1 & 3 & 3 & 3 & 2 & 3 & 4.8455 & 1.0620 & 5.530 & 13.706 & -0.522 & -14.855 \\
\hline 32 & 2 & 2 & 1 & 1 & 1 & 3 & 1 & 2.3034 & 1.9914 & 4.988 & 7.2474 & -5.983 & -13.959 \\
\hline 33 & 2 & 3 & 2 & 2 & 2 & 1 & 2 & 4.4988 & 0.0510 & 8.635 & 13.061 & 25.848 & -18.725 \\
\hline 34 & 2 & 1 & 3 & 1 & 2 & 3 & 2 & 4.4204 & 3.7062 & 4.995 & 12.909 & -11.37 & -13.971 \\
\hline 35 & 2 & 2 & 1 & 2 & 3 & 1 & 3 & 2.5422 & 0.0309 & 5.646 & 8.1042 & 30.200 & -15.035 \\
\hline 36 & 2 & 3 & 2 & 3 & 1 & 2 & 1 & 3.1368 & 0.0371 & 7.081 & 9.9297 & 28.612 & -17.002 \\
\hline
\end{tabular}

\subsection{Material Removal Rate}

The value of $S / N$ ratio corresponding to MRR is shown in Tab. 4.

Table 5 ANOVA results for MRR

\begin{tabular}{|c|c|c|c|c|c|c|}
\hline Source & $d f^{*}$ & $\begin{array}{c}S e q . \\
S S^{*}\end{array}$ & $\begin{array}{c}\text { Adj. } \\
M S^{*}\end{array}$ & $F^{*}$ & $p^{*}$ & $\begin{array}{c}\text { Percentage } \\
\text { Contribution }\end{array}$ \\
\hline$D_{\mathrm{F}}$ & 1 & 1.18 & 1.1803 & 0.37 & 0.548 & 0.587644 \\
\hline$T_{\mathrm{on}}$ & 2 & 6.23 & 3.1148 & 0.98 & 0.39 & 3.102559 \\
\hline$I_{\mathrm{d}}$ & 2 & 83.403 & 41.701 & 13.16 & 0 & 41.53494 \\
\hline$\zeta$ & 2 & 1.886 & 0.9431 & 0.3 & 0.746 & 0.939234 \\
\hline$V_{\mathrm{g}}$ & 2 & 7.066 & 3.533 & 1.11 & 0.346 & 3.518889 \\
\hline$T_{\mathrm{M}}$ & 2 & 6.453 & 3.2263 & 1.02 & 0.378 & 3.213613 \\
\hline$T_{\mathrm{L}}$ & 2 & 24.852 & 12.426 & 3.92 & 0.035 & 12.37637 \\
\hline $\begin{array}{c}\text { Residual } \\
\text { Error }\end{array}$ & 22 & 69.732 & 3.1696 & & & \\
\hline Total & 35 & 200.802 & & & & \\
\hline
\end{tabular}

*df - Degree of freedom, Seq. SS - Sum of Square, Adj MS' - Adjusted

Mean Square, $F-F$ value ( $95 \%$ confidence interval), $p$ - $p$ value
ANOVA results for the same, shown in Tab. 5, indicate that discharge current is the most influencing parameter having percentage contribution as $41.53 \%$ followed by tool electrode lift time and tool material.

Fig. 4a depicts that MRR increases with increase in discharge current. This may be attributed to the fact that the increase in discharge current increases the spark energy between the electrode and the work piece. High spark energy increases the temperature that ultimately leads to higher $M R R$. Fig. $4 \mathrm{~b}$ depicts that $M R R$ increases with increase in tool electrode lift time. Low tool electrode lift time causes carbon accumulation on the electrode face resulting in more sparks at the surface that ultimately leads to less MRR. Increment in tool lifting time increases the inter-electrode gap (IEG) between tool and work piece that leads to higher $M R R$. Fig. 4c shows that $M R R$ is affected by tool material. High $M R R$ is achieved by Gr electrode followed by $\mathrm{CuW}$ and $\mathrm{Cu}$. This may be attributed to the fact that $M R R$ is affected by tool material's thermo-physical 
properties like melting point, density, strength, electrical conductivity.

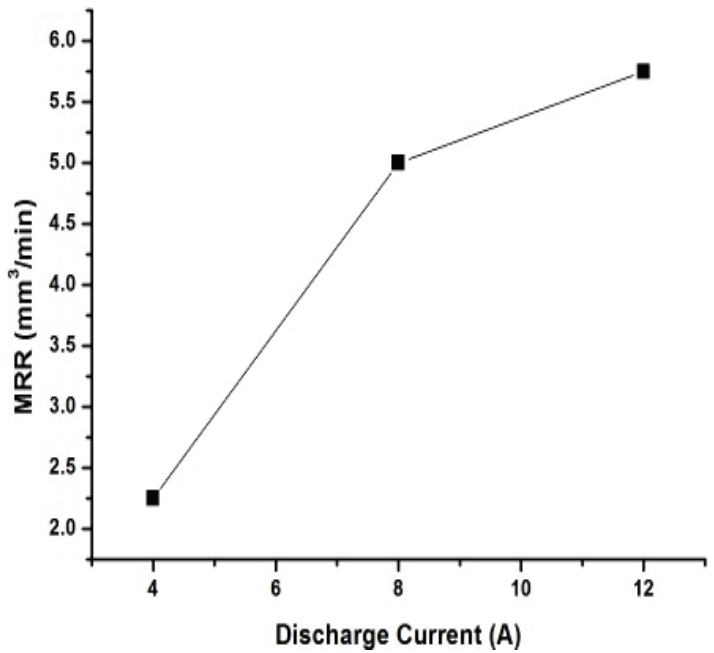

(a)

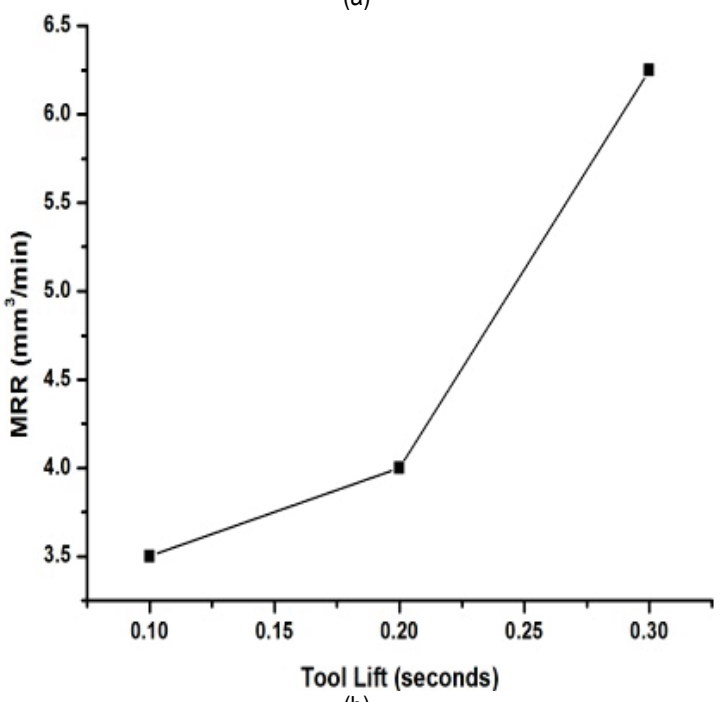

(b)

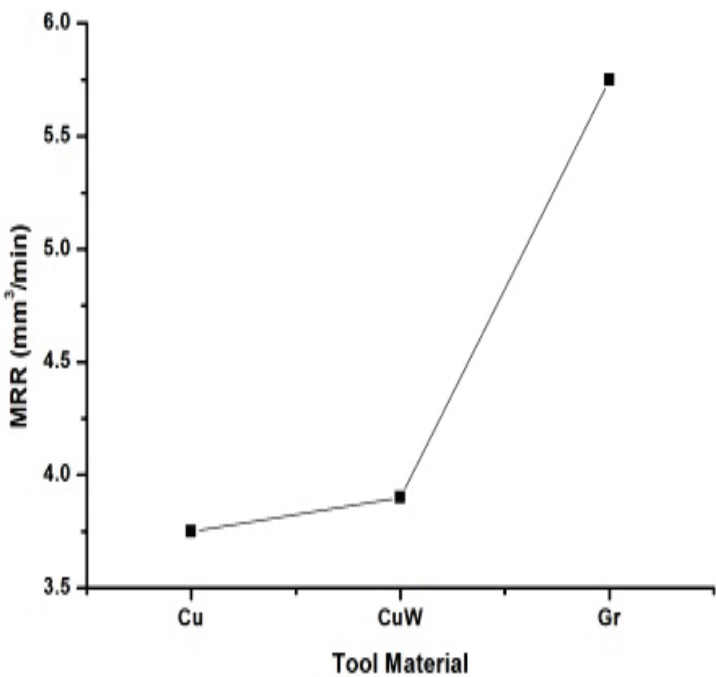

(c)

Figure 4 (a) MRR vs Discharge current; (b) MRR vs Tool lift; (c) MRR vs Tool material

\subsection{Surface Roughness}

The value of $S / N$ ratio corresponding to $S R$ is shown in Tab. 4. ANOVA results for the same, shown in Tab. 6, indicate that pulse-on-time is the most influential parameter having percentage contribution as $54.79 \%$ followed by discharge current and tool material.

\begin{tabular}{|c|c|c|c|c|c|c|}
\hline Table 6 ANOVA results for SR \\
\hline Source & $d f$ & Seq. SS & Adj. MS & $F$ & $p$ & $\begin{array}{c}\text { Percentage } \\
\text { Contribution }\end{array}$ \\
\hline$D_{\mathrm{F}}$ & 1 & 0.0094 & 0.0094 & 0.04 & 0.850 & 0.01645 \\
\hline$T_{\mathrm{on}}$ & 2 & 31.2931 & 15.6466 & 61.02 & 0.000 & 54.7924 \\
\hline$I_{\mathrm{d}}$ & 2 & 14.8950 & 7.4475 & 29.04 & 0.000 & 26.080 \\
\hline$\zeta$ & 2 & 0.2564 & 0.1282 & 0.50 & 0.613 & 0.4489 \\
\hline$V_{\mathrm{g}}$ & 2 & 0.7485 & 0.3743 & 1.46 & 0.254 & 1.3105 \\
\hline$T_{\mathrm{M}}$ & 2 & 3.9398 & 1.9699 & 7.68 & 0.003 & 6.8983 \\
\hline$T_{\mathrm{L}}$ & 2 & 0.3284 & 0.1642 & 0.64 & 0.537 & 0.5750 \\
\hline $\begin{array}{c}\text { Residual } \\
\text { Error }\end{array}$ & 22 & 5.6414 & 0.2564 & & & \\
\hline Total & 35 & 57.1121 & & & & \\
\hline
\end{tabular}

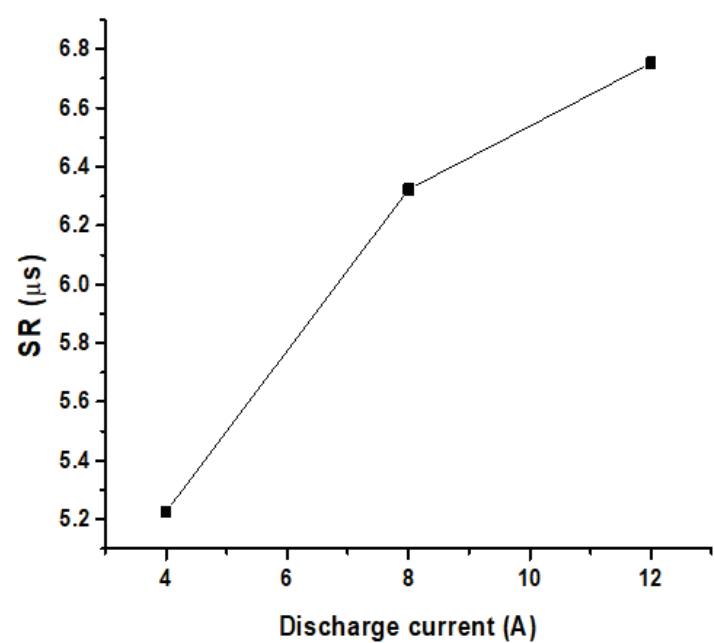

(a)

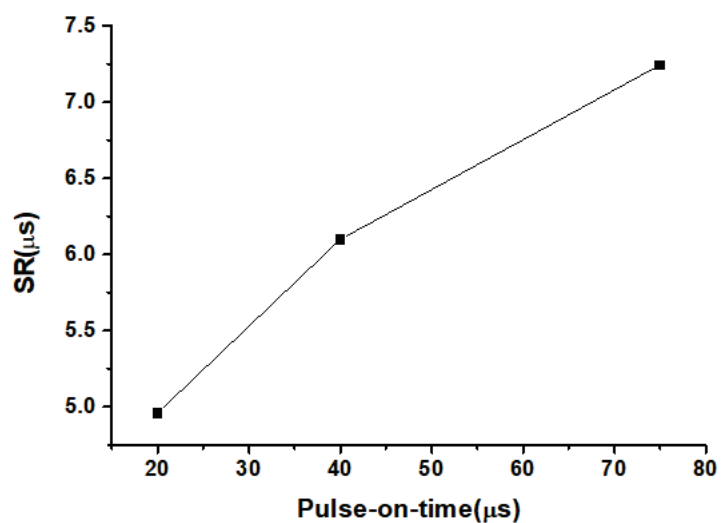

(b)

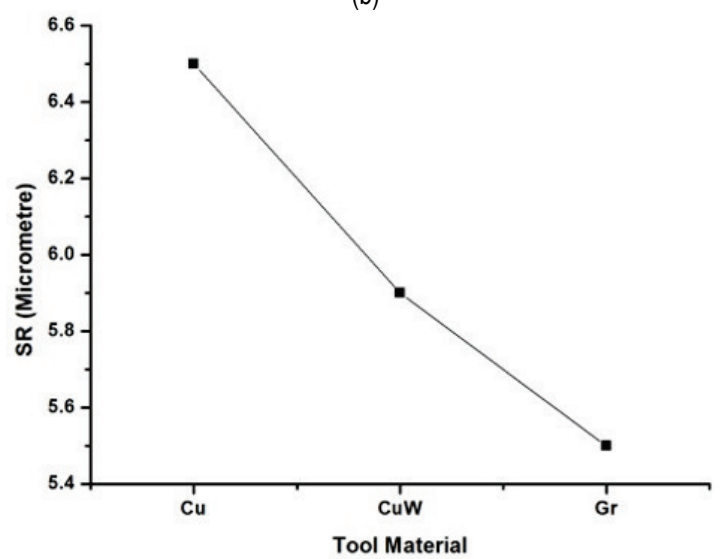

(c)

Figure 5 (a) $S R$ vs Discharge current; (b) $S R$ vs Pulse-on-time; (c) $S R$ vs Tool material 
Fig. 5a and 5b indicates that $S R$ increases with increase in discharge current and pulse-on-time. $S R$ is nothing but the formation of small craters at the surface due to spark discharges. Spark discharges are proportional to the discharge energy and discharge duration i.e. discharge current and pulse-on-time respectively. More is the value of discharge current and pulse-on-time more will be the $S R$. Fig. 5c reveals that $S R$ is also affected by tool material. $S R$ is highest for $\mathrm{Cu}$ electrode and lowest for $\mathrm{Gr}$ electrode. The thermo-physical properties of the tool material play a crucial role in the variation of surface roughness. The parameters like thermal conductivity, density and specific heat are very much effective in deciding the $S R$ value.

\subsection{Tool Wear Rate}

The value of $S / N$ ratio corresponding to $T W R$ is shown in Tab. 4. ANOVA results for the same, shown in Tab. 7, indicate that tool material is the most influencing parameter having percentage contribution of $49.87 \%$ followed by pulse-on-time and discharge current.

Table 7 ANOVA results for TWR

\begin{tabular}{|c|c|c|c|c|c|c|}
\hline Source & $d f$ & Seq. SS & Adj. MS & $F$ & $p$ & $\begin{array}{c}\text { Percentage } \\
\text { Contribution }\end{array}$ \\
\hline$D_{\mathrm{F}}$ & 1 & 4.79 & 4.7899 & 4.32 & 0.05 & 4.566428 \\
\hline$T_{\mathrm{on}}$ & 2 & 8.934 & 4.4671 & 4.03 & 0.032 & 8.517007 \\
\hline$I_{\mathrm{d}}$ & 2 & 7.56 & 3.7798 & 3.41 & 0.051 & 7.207138 \\
\hline$\zeta$ & 2 & 1.687 & 0.8433 & 0.76 & 0.479 & 1.60826 \\
\hline$V_{\mathrm{g}}$ & 2 & 4.567 & 2.2837 & 2.06 & 0.151 & 4.353836 \\
\hline$T_{\mathrm{M}}$ & 2 & 52.321 & 26.1604 & 23.6 & 0 & 49.87893 \\
\hline$T_{\mathrm{L}}$ & 2 & 0.652 & 0.3259 & 0.29 & 0.748 & 0.621568 \\
\hline $\begin{array}{c}\text { Residual } \\
\text { Error }\end{array}$ & 22 & 24.386 & 1.1084 & & & \\
\hline Total & 35 & 104.896 & & & & \\
\hline
\end{tabular}

Fig. 6a indicates that $T W R$ increases with increase in discharge current because higher discharge current value produces more sparks resulting in high heat formation causing more material removal rate from the work piece and tool electrode. Fig. 6b indicates that increase in pulseon-time reduces tool wear reduces. This may be attributed to the reason that as pulse-on-time increases, spark (in plasma channel) spreads thus reduces the amount of heat transferred to the tool resulting in low TWR. Fig. 6c shows that $T W R$ is minimum for $\mathrm{CuW}$ electrode and maximum for Gr electrode.

This may be attributed to the thermo-physical properties of the tool electrode. High melting point, higher density and good thermal conductivity of the electrode material will lead to low tool wear rate.

\section{SURFACE CHARACTERISATION 4.1 Scanning Electron Microscopy (SEM)}

EDM surface is generally matte in nature comprised of multitude layers of the crater, pockmarks, re-solidify layer, debris, spherical droplets etc. In this work, SEM analysis has been carried out to study the features like microstructure, topography, morphology and fractography with a range from millimetre to nanometre. Six samples with three different electrode materials have been taken and analysed. Fig. 7a, b and c show the SEM analysis for Inconel 825 machined using $\mathrm{Cu}$ electrode, (4 A, 8 A current), (20 $\mu \mathrm{s}, 75 \mu$ s pulse-on-time), $(40 \mathrm{~V}, 60 \mathrm{~V}$ gap voltage), (10 tau, 11 tau duty factor), $(0.1 \mathrm{~s}, 0.2 \mathrm{~s}$ tool lift time). The SEM images show the wavy in nature indicating the presence of crater varying in size from smaller to bigger crater due to low and high intensity of current and pulseon-time. The images also show the presence of white spot formation on a large scale indicating that are-solidification phenomenon is dominating one. The topography also presents a river bed pattern along with pockmarks which is a property of erosion phenomena [25].

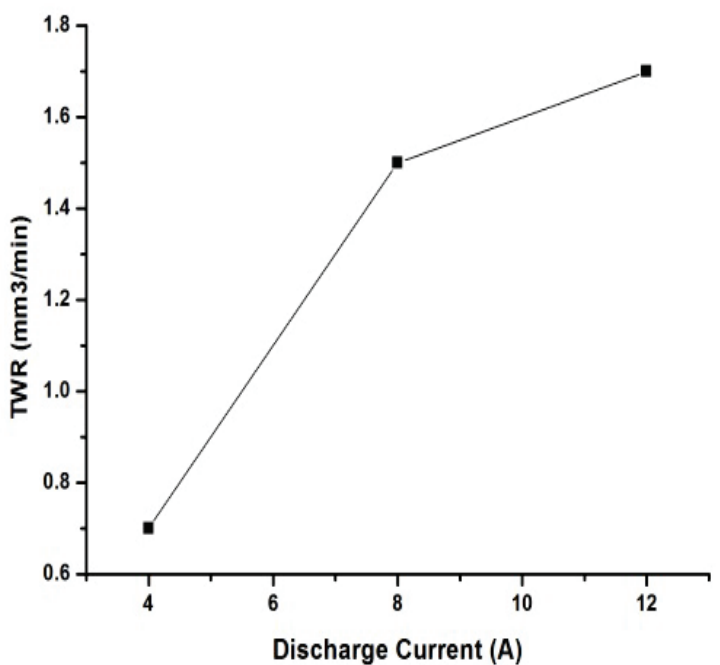

(a)

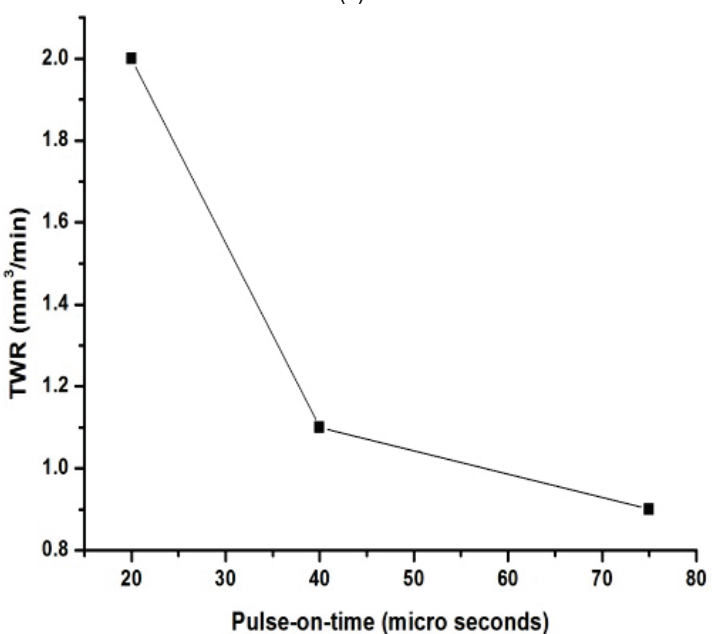

(b)

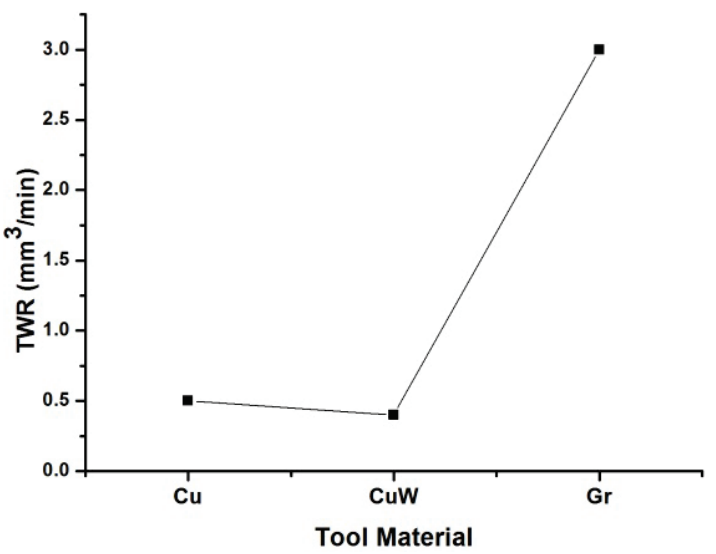

(c)

Figure 6 (a) TWR vs Tool material; (b) TWR vs Pulse-on-time; (c) TWR vs Discharge current 


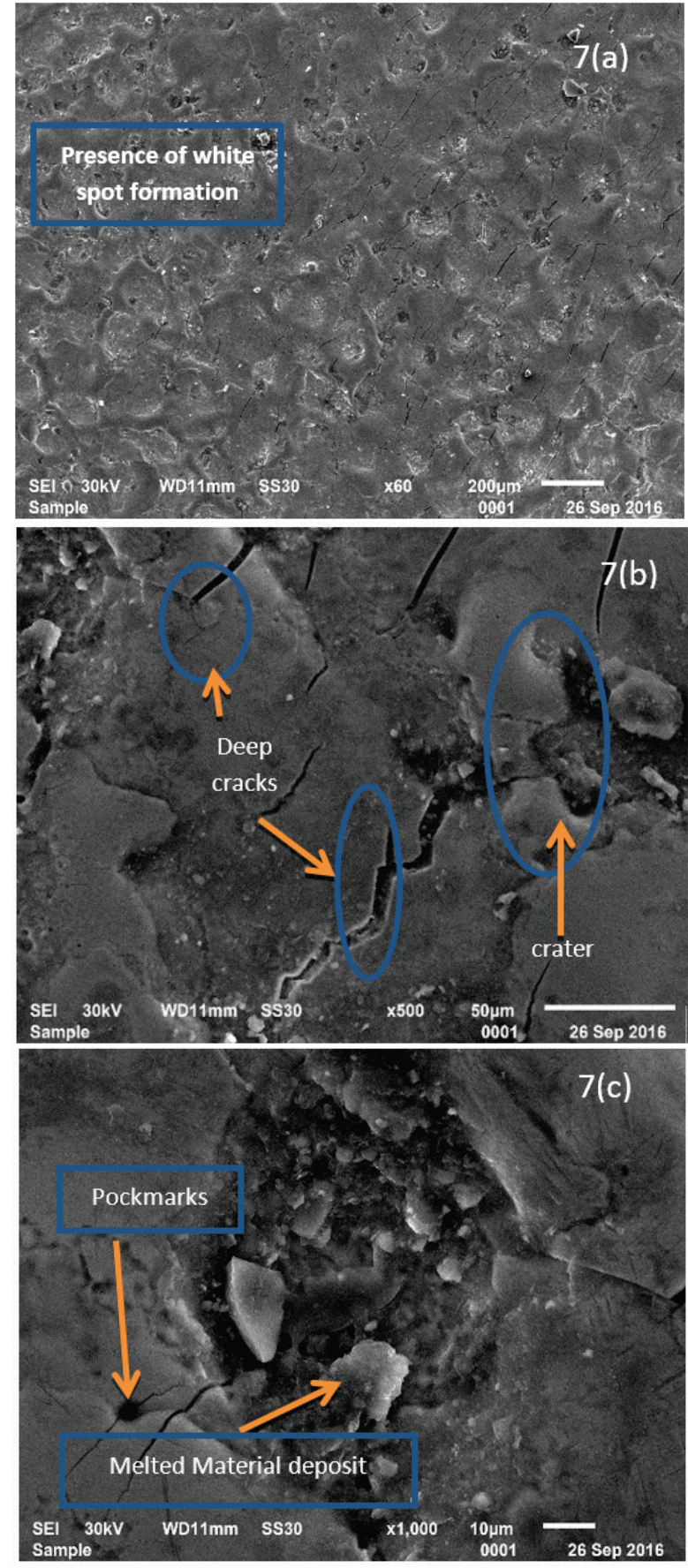

Figure 7 (a) (b) (c) SEM Micrograph of EDM surface with Cu electrode

Fig. 8a, b and c show the micrograph view of the EDM surface machined by $\mathrm{Cu}-\mathrm{W}$ electrode under the varying conditions such as (4 A, 8 A current), $(40 \mu \mathrm{s}, 75 \mu \mathrm{s}$ pulseon-time), $(80 \mathrm{~V}, 40 \mathrm{~V}$ gap voltage), (10 tau,12 tau duty factor $),(0.3 \mathrm{~s}, 0.1 \mathrm{~s}$ tool lift time $)$. SEM images show that it corresponds to three different types of areas such as dark zone, grey zone and white zone. The area corresponding to dark zone indicates that deep craters are formed due to high pulse current and high pulse-on-time causing more evaporation and melting simultaneously resulting with more MRR from the surface, whereas the area marked with grey zone confirms the presence of shallow craters along with heat affected zone. The area with white zone indicates the formation of the white layer due to re-solidification phenomenon. The fascinating images obtained by using $\mathrm{CuW}$ electrode show some attractive features like minimum surface roughness amongst the other two electrodes. Fig. 8c shows the SEM image of a two cracks meeting at a point. The morphology indicates the tearing phenomena causing the residual stress to exceed the ultimate tensile stress.
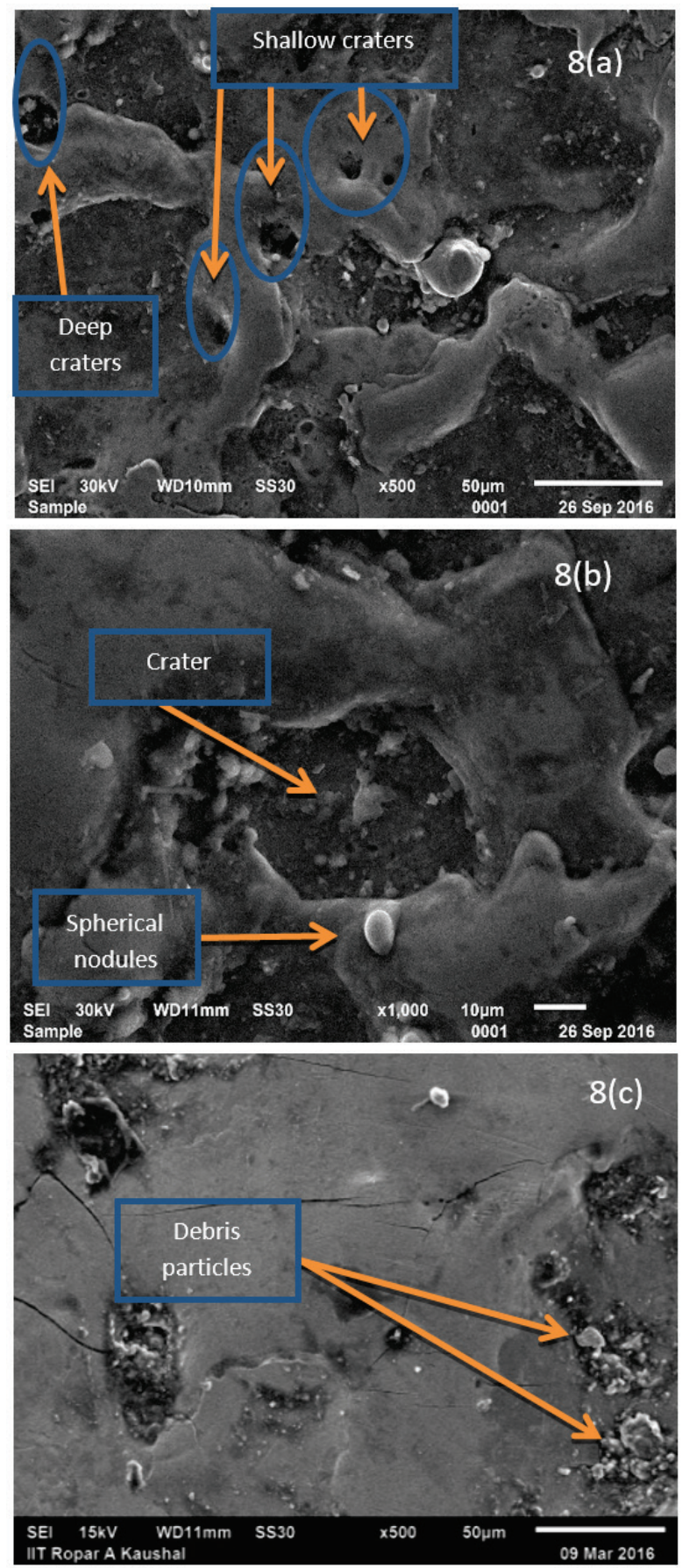

Figure 8 (a) (b) (c) SEM Micrograph of EDM surface with Cu-W electrode

Fig. 9a, $b$ and $\mathrm{c}$ represent the SEM image of work piece machined by $\mathrm{Gr}$ electrode at ( $8 \mathrm{~A}$, current $),(40 \mu \mathrm{s}$, pulseon-time $),(60 \mathrm{~V}, 80 \mathrm{~V}$ gap voltage), (11 tau, 12 tau duty factor), ( $0.3 \mathrm{~s}, 0.2 \mathrm{~s}$ tool lift time). The micrograph shows the presence of overlapping craters with variation in sizes along with micro crack present throughout work piece. It is evident from the machining process that by sudden heating there is loosening of the substance all along the grain boundary. Since the grain boundaries are weak, the material gets easily chipped off [26]. This fact is confirmed from the SEM image Fig. 9b taken at higher magnification 
which indicates that there are patches of craters of bigger size lying on the surface. The SEM image also confirms the presence of cracks formed due to thermal stresses.
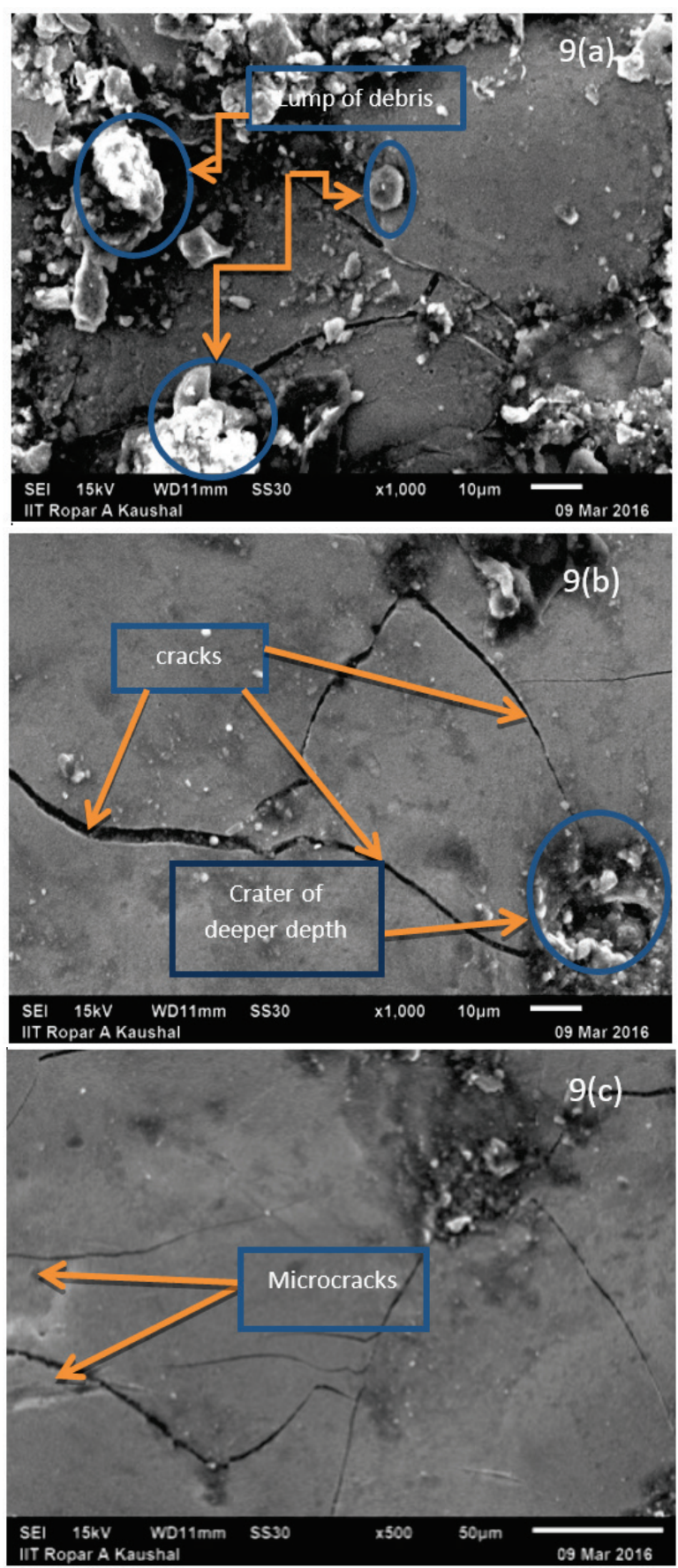

Figure 9 (a) (b) (c) SEM Micrograph of EDM surface with Gr electrode

\subsection{Energy-Dispersive X-Ray Spectroscopy (EDXS)}

EDXS is used for observing the transfer/migration of material from the dielectric and tool electrode. In the present study, the work piece is machined by three types of electrode material i.e. $\mathrm{Cu}, \mathrm{CuW}$ and $\mathrm{Gr}$. An EDXS analysis shows that material is transferred to the work piece from electrodes surface which is continuously flushed out by the flow of dielectric fluid. It also confirms that percentage of carbon in EDM surface is high due to low pulse current and high pulse-on-time i.e. $4 \mathrm{~A}$ and $75 \mu$ s as shown in Fig. 10a-d.

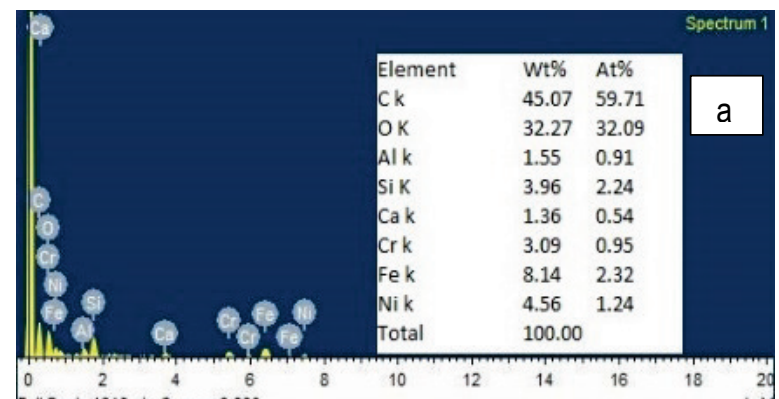

0
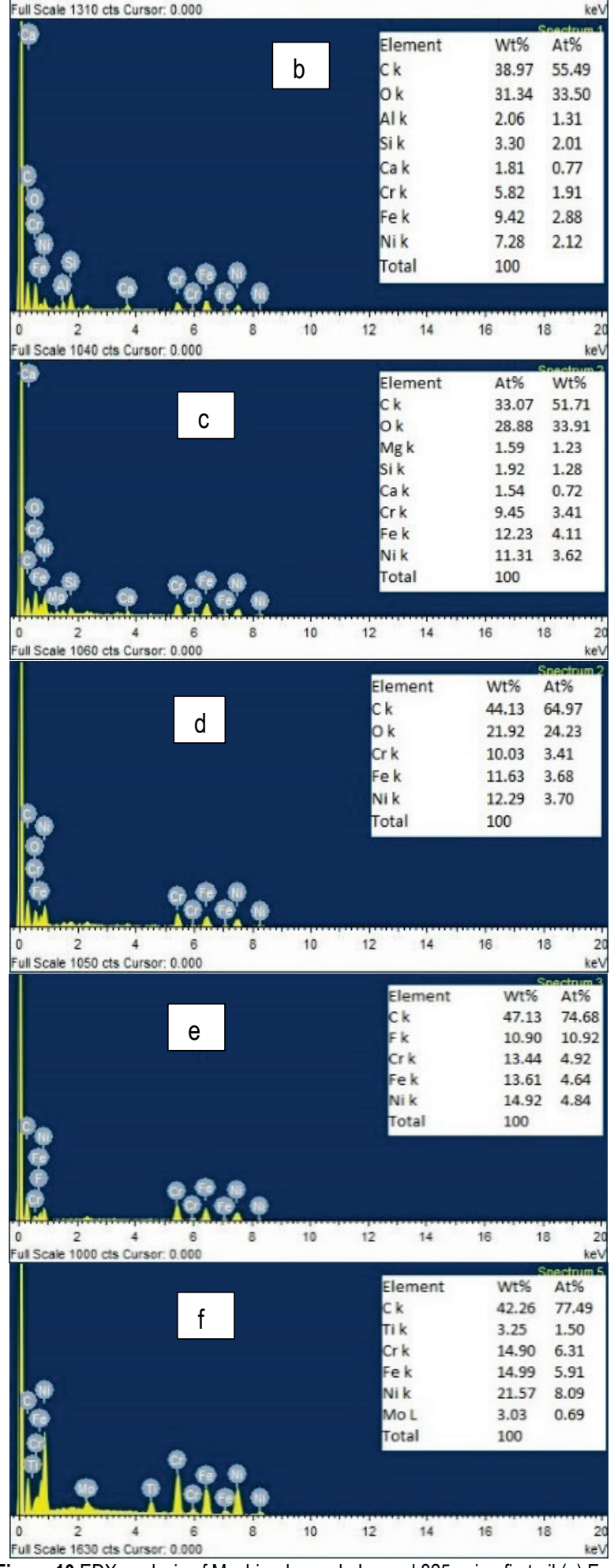

Figure 10 EDX analysis of Machined sample Inconel 825 using first oil (a) Exp. No.1 Cu electrode; (b) Exp. No.5 Gr electrode; (c) Exp. No.11 CuW electrode then by Second oil; (d) Exp. No.29 Gr electrode; (e) Exp. No.33 Cu electrode; (f) Exp. No.36 CuW electrode 
At low current and high pulse on time, pyrolysis effect of the dielectric fluid increases resulting in more carbon percentage on the EDMed surface. The formation of oxide takes place when oxygen attacks and degrades the EDM fluids. From Fig. 10e-f of EDXS analysis, the higher peaks represent the concentrated elements found in the work sample. EDXS results are indicated by the percentage of elements transfer from electrode and dielectric to the work piece. The EDX analysis also reveals that major contributions are Carbon (C), Oxygen $\left(\mathrm{O}_{2}\right)$, Iron $(\mathrm{Fe})$, Nickel (Ni), Chromium (Cr) and little amount of Molybdenum (Mo) which is transferred to the surface of the work piece. The higher percentage contribution is shown by the oxygen and carbon which is generally due to the disintegration of dielectric, oxidation and the amount of debris removed at a high temperature in EDM process.

\subsection{X-Ray Diffraction (XRD)}

XRD analysis has been done for the machined surface to examine the nature of compounds formed. For this, selected samples were examined by XRD. The variation and phases in the diffraction peaks were analysed by observing $2 \theta$ scale value such as $43.560,50.718,63.66$, 70.68, 80.696 and 81.285. Inconel 825 machined with $\mathrm{Cu}$ electrode and oil 1 (Exp. No.1) is shown in Fig. 11a.

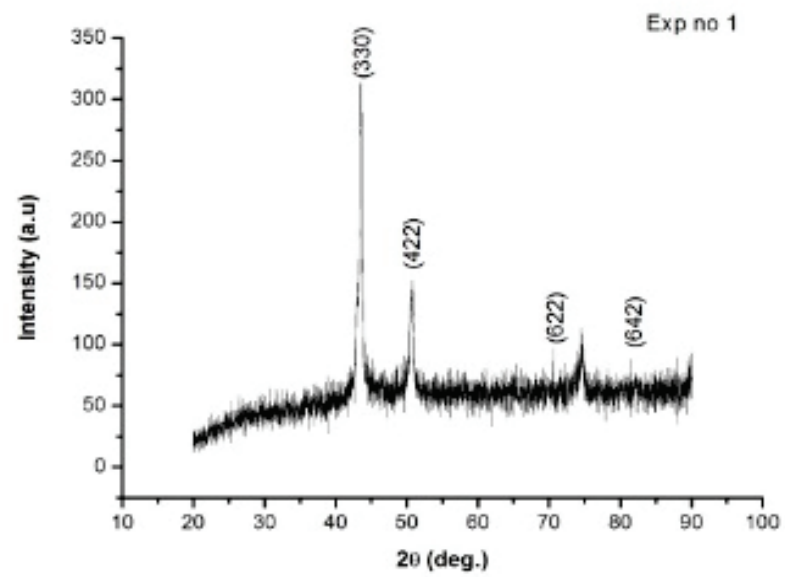

Figure 11(a) XRD Pattern of Machined sample using first oil, Exp. No.1 Cu electrode

The experimental runs are designed in such a way that, for every trial, there is a variation of input factors such as pulse-on time (10 $\mu \mathrm{s}-75 \mu \mathrm{s})$, discharge current from (4 A - $12 \mathrm{~A})$ and gap voltage $(40 \mathrm{~V}-80 \mathrm{~V})$ which results into the formation of bcc structure of the $\gamma$-phase of Inconel 825 along with some $\delta\left(\mathrm{Ni}_{3} \mathrm{Al}\right)$ phase at a diffraction angle of $43.5^{\circ}$. The formation of intermetallic phase at $63.6^{\circ}$ is because of the transfer of elements from tool as well as from dielectric used in the experiment which is a similar observation reported by Talla G. et al. [27]. The intermetallic phase $\left(\mathrm{Ni}_{3} \mathrm{Al}\right)$ will offer superior material properties such as high hardness, tensile strength and high creep strength [28]. The lattice planes are indexed as (300), (422), (622), (642) and the compound as $\mathrm{Cr}_{12} \mathrm{Fe}_{22} \mathrm{Mo}_{4} \mathrm{NbNi}_{10} \mathrm{Si}_{9}$. The pattern shows traces of chromium, iron, molybdenum, niobium, silicon and nickel on the machined surface. The chromium acts as an oxidizing agent whereas nickel, molybdenum and niobium act as resistance to reducing environment and for pitting and crevice corrosion. In the second observation with $\mathrm{Gr}$ electrode and oil 1 (Exp. No.5) is shown in Fig. 11b.

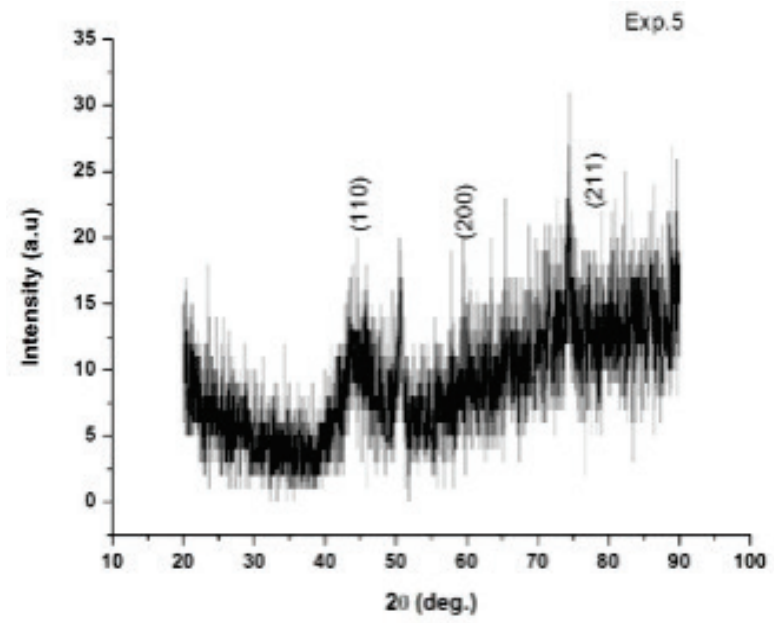

Figure 11(b) XRD Pattern of Machined sample using first oil, Exp. No.5 Gr electrode

The variation in the peak with varying input factors showed the presence of a $B C C$ structure with martensitic phase. The martensitic phase occurs during the EDM process as the machining takes place at high heat energy (high current and high pulse-on-time) causing the material to get melt down and simultaneously get cooled down with the help of dielectric. The lattice planes are indexed as (110), (200), (211) and the compound formed as $\mathrm{C}_{0.60} \mathrm{Cr}_{1.13} \mathrm{Fe}_{8.5} \mathrm{Mn}_{0.8} \mathrm{Mo}_{0.04} \mathrm{Nb}_{0.01} \mathrm{Ni}_{0.08} \mathrm{Si}_{0.7} \mathrm{~V}_{0.02}$.

The pattern shows the presence of carbon on the machined surface which is acting as hardening agent. It, therefore, increases wear resistance to the work sample as well as reduces toughness and ductility. The carbon has the tendency for maximum solubility in austenite region. Similarly, when machined with $\mathrm{CuW}$ electrode and oil 1 (Exp. No.11) is shown in Fig. 11c.

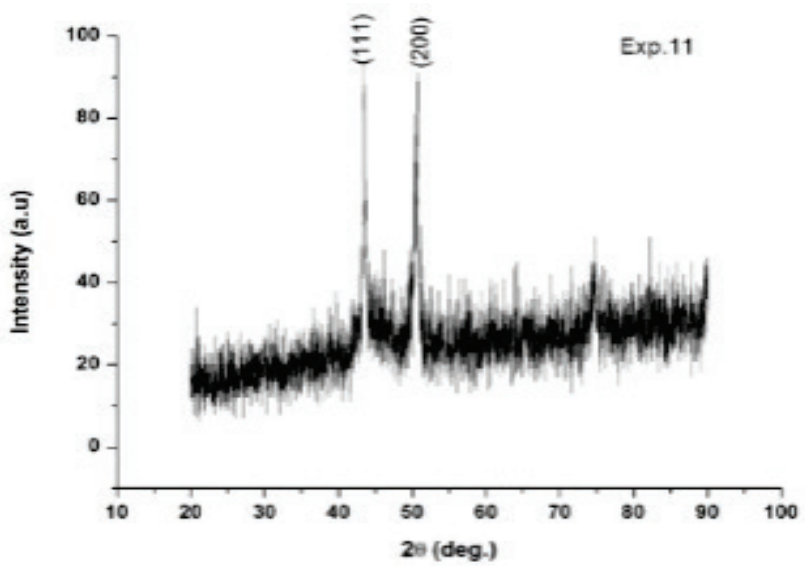

Figure 11(c) XRD Pattern of Machined sample using first oil, Exp. No.11 CuW electrode

It is forming an $F C C$ structure with change in phase transformation from $B C C$ to $F C C$. This may be due to generation of high temperature (high peak current) at the machining zone which causes the material to become soft and ductile and causes more carbon to absorb. The lattice planes are indexed as (111), (200) and the compound as $\mathrm{Cr}_{2} \mathrm{Fe}_{6.7} \mathrm{Mo}_{0.1} \mathrm{Ni}_{1.3} \mathrm{Si}_{0.3}$. The observations of $\mathrm{Cu}, \mathrm{Gr}$ and $\mathrm{CuW}$ from second oil (Exp. No.29, 33, 36) are forming the 
same compound as of first oil with $\mathrm{Cu}$ electrode by showing the same phase as $\mathrm{Cr}_{12} \mathrm{Fe}_{22} \mathrm{MO}_{4} \mathrm{NbNi}_{10} \mathrm{Si}_{9}$. Refer to Fig. 11d.

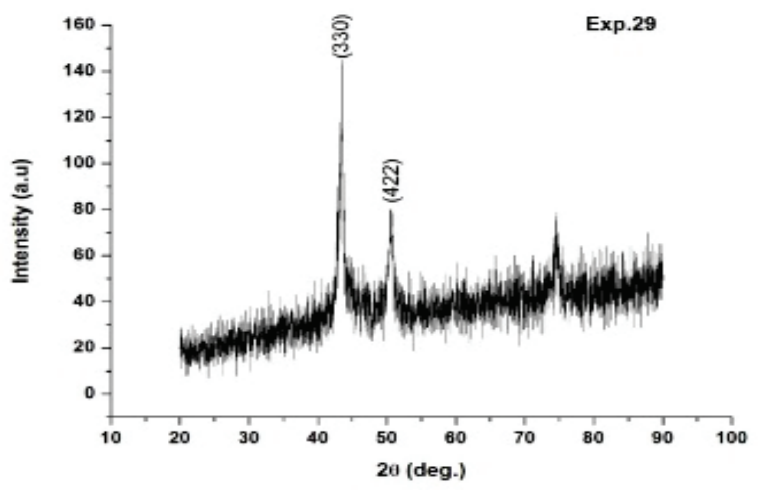

Figure 11(d) XRD Pattern of Machined sample using first oil using second oil Exp. No.29, 33, 36

\section{OPTIMISATION BY TOPSIS METHOD \\ 5.1 TOPSIS Method}

TOPSIS Method is one of the multi criteria decision making methods [29]. It awards rank to different solutions. Highest ranked solutions are taken as the optimal solution. The steps to solve a problem using TOPSIS are briefly discussed in the following section along with a mathematical illustration. In this work, authors have evaluated factors (which are input parameters) with an objective to achieve higher $M R R$ and lower $S R$ for 36 experimental runs that are considered as alternatives. The best alternative is the one closest to the ideal solution and worst is the one farthest from the ideal solution.

Step 1. The results obtained after conducting experiments were used to make a decision matrix. The decision matrix consists of values of $M R R$ and $S R$ corresponding to different combinations of input parameters. Hence, the decision matrix, in this work, has been taken from Tab. 4.

Step 2. The above decision matrix is normalized using Eq. (1) and is shown in Tab. 8 .

$$
r_{i j}=\frac{x_{i j}}{\sum_{i=1}^{m} x_{i j}^{2}}
$$

(for $i=1$ to $m ; j=1$ to $n$ )

Step 3. Weight is considered 0.5 for both $M R R$ and $S R$. Weighted normalized decision matrix is calculated using Eq. (2).

$v_{i j}=w_{j} r_{i j}$

( $i=1$ to $m ; j=1$ to $n ; w_{j}$ is the weight of $j$ criterion)

Step 4. Determine positive ideal solution represented by PIS $\left(A^{*}\right)$ and negative ideal solution represented by NIS ( $\bar{A}$ ) using Eqs. (3a) and (3b)

$A^{*}=\left\{v_{1}^{*}, v_{2}^{*}, \ldots, v_{j}^{*}, \ldots, v_{n}^{*}\right\}=$

$=\left\{\left(\max v_{i j} \mid j \varepsilon J_{1}\right),\left(\min v_{i j} \mid j \varepsilon J_{2}\right) i=1, \ldots, m\right\}$

PIS: $A^{*}=\{0.0029 ; 0.4742 ; 0.1232 ; 0.0058 ; 0.4368$; $0.004944 ; 0.0205\}$

$\bar{A}=\left\{\bar{v}_{1}, \bar{v}_{2}, \ldots, \bar{v}_{j}, \ldots, \bar{v}_{n}\right\}=$

$=\left\{\left(\min v_{i j} \mid j \varepsilon J_{1}\right),\left(\max v_{i j} \mid j \varepsilon J_{2}\right) i=1, \ldots, m\right\}$

NIS: $\bar{A}=\{0.0137 ; 0.2390 ; 0.0057 ; 0.0020 ; 0.1576$; $0.000855 ; 0.0029\}$

Step 5. Separation distance for each alternative from Positive and Negative Ideal Solution is calculated using Eq. (4) and is shown in Tab. 9.

$S_{i}^{*}=\sqrt{\sum_{j=1}^{n}\left(v_{i j}-v_{j}^{*}\right)^{2}}, \bar{S}_{i}=\sqrt{\sum_{j=1}^{n}\left(v_{i j}-\bar{v}_{j}\right)^{2}}$

where, $i=1$ to $m$

Step 6. Relative closeness to ideal solution $C_{i}^{*}$ is calculated using Eq. (5) and is shown in Tab. 9.

$$
C_{i}^{*}=\frac{\bar{S}_{i}}{S_{i}^{*}+\bar{S}_{i}}
$$

Table 8 Normalized decision matrix

\begin{tabular}{|c|c|c|c|c|c|c|c|}
\hline Experiments & $D_{\mathrm{F}}$ & $T_{\mathrm{on}} / \mu \mathrm{s}$ & $I_{\mathrm{D}} / \mathrm{A}$ & $\zeta / \%$ & $V_{\mathrm{g}} / \mathrm{V}$ & $T_{\mathrm{M}} / \mathrm{s}$ \\
\hline 1 & 0.021729 & 0.434576 & 0.086915 & 0.217288 & 0.869153 & 0.021729 & 0.002173 \\
\hline 2 & 0.013621 & 0.544834 & 0.108967 & 0.149829 & 0.817251 & 0.027242 \\
\hline 3 & 0.009008 & 0.675618 & 0.108099 & 0.108099 & 0.72066 & 0.027025 & 0.002702 \\
\hline 4 & 0.021713 & 0.434266 & 0.086853 & 0.217133 & 0.868531 & 0.043427 & 0.004343 \\
\hline 5 & 0.013614 & 0.544579 & 0.108916 & 0.149759 & 0.816868 & 0.040843 & 0.004084 \\
\hline 6 & 0.009011 & 0.67584 & 0.108134 & 0.108134 & 0.720896 & 0.009011 & 0.000901 \\
\hline 7 & 0.012005 & 0.240093 & 0.048019 & 0.132051 & 0.960374 & 0.012005 & 0.002401 \\
\hline 8 & 0.017117 & 0.684678 & 0.136936 & 0.205403 & 0.684678 & 0.034234 & 0.005135 \\
\hline 9 & 0.010271 & 0.770335 & 0.123254 & 0.102711 & 0.616268 & 0.030813 \\
\hline 10 & 0.0155 & 0.310009 & 0.062002 & 0.186005 & 0.930027 & 0.015500 & 0.001027 \\
\hline 11 & 0.011064 & 0.442563 & 0.088513 & 0.110641 & 0.885126 & 0.022128 & 0.00465 \\
\hline 12 & 0.011547 & 0.866023 & 0.138564 & 0.127017 & 0.461879 & 0.034641 & 0.002309 \\
\hline 13 & 0.021233 & 0.424664 & 0.169866 & 0.254798 & 0.849328 & 0.063700 & 0.004247 \\
\hline 14 & 0.013551 & 0.542023 & 0.162607 & 0.135506 & 0.813034 & 0.013551 & 0.004065 \\
\hline 15 & 0.009066 & 0.679938 & 0.036263 & 0.099724 & 0.725267 & 0.018132 & 0.000907 \\
\hline 16 & 0.013596 & 0.543827 & 0.108765 & 0.163148 & 0.815741 & 0.013596 & 0.00136 \\
\hline 17 & 0.01101 & 0.440411 & 0.132123 & 0.110103 & 0.880822 & 0.022021 & 0.002202 \\
\hline 18 & 0.011647 & 0.873506 & 0.046587 & 0.128114 & 0.46587 & 0.034940 & 0.003494 \\
\hline 19 & 0.023944 & 0.239438 & 0.095775 & 0.119719 & 0.957751 & 0.035916 & 0.003592 \\
\hline
\end{tabular}


Table 8 Normalized decision matrix (continuous)

\begin{tabular}{|c|c|c|c|c|c|c|c|}
\hline Experiments & $D_{\mathrm{F}}$ & $T_{\text {on }} / \mu \mathrm{s}$ & $I_{\mathrm{D}} / \mathrm{A}$ & $\zeta / \%$ & $V_{\mathrm{g}} / \mathrm{V}$ & $T_{\mathrm{M}}$ & $T_{\mathrm{L}} / \mathrm{s}$ \\
\hline 20 & 0.033952 & 0.679039 & 0.203712 & 0.186736 & 0.679039 & 0.016976 & 0.001698 \\
\hline 21 & 0.020636 & 0.773852 & 0.041272 & 0.123816 & 0.619082 & 0.020636 & 0.002064 \\
\hline 22 & 0.023908 & 0.23908 & 0.095632 & 0.131494 & 0.956319 & 0.035862 & 0.001195 \\
\hline 23 & 0.03384 & 0.676797 & 0.203039 & 0.203039 & 0.676797 & 0.016920 & 0.003384 \\
\hline 24 & 0.020685 & 0.775669 & 0.041369 & 0.103423 & 0.620535 & 0.020685 & 0.003103 \\
\hline 25 & 0.041949 & 0.41949 & 0.251694 & 0.23072 & 0.83898 & 0.041949 & 0.006292 \\
\hline 26 & 0.027285 & 0.545696 & 0.05457 & 0.163709 & 0.818545 & 0.040927 & 0.001364 \\
\hline 27 & 0.018112 & 0.679184 & 0.072446 & 0.090558 & 0.724463 & 0.009056 & 0.001811 \\
\hline 28 & 0.030592 & 0.305923 & 0.183554 & 0.168258 & 0.91777 & 0.030592 & 0.015296 \\
\hline 29 & 0.022117 & 0.442347 & 0.044235 & 0.132704 & 0.884694 & 0.033176 & 0.022117 \\
\hline 30 & 0.023245 & 0.871681 & 0.092979 & 0.116224 & 0.464896 & 0.011622 & 0.034867 \\
\hline 31 & 0.023727 & 0.237273 & 0.142364 & 0.142364 & 0.949091 & 0.023727 & 0.035591 \\
\hline 32 & 0.034658 & 0.693167 & 0.069317 & 0.173292 & 0.693167 & 0.051988 & 0.017329 \\
\hline 33 & 0.020608 & 0.772785 & 0.08243 & 0.113342 & 0.618228 & 0.010304 & 0.020608 \\
\hline 34 & 0.030639 & 0.30639 & 0.183834 & 0.153195 & 0.919169 & 0.045958 & 0.030639 \\
\hline 35 & 0.022153 & 0.443052 & 0.044305 & 0.121839 & 0.886104 & 0.011076 & 0.033229 \\
\hline 36 & 0.023184 & 0.869394 & 0.092735 & 0.139103 & 0.463677 & 0.023184 & 0.011592 \\
\hline
\end{tabular}

PIS: $A^{*}=\{0.0210 ; 0.4368 ; 0.1258 ; 0.1274 ; 0.4802 ; 0.031850 ; 0.0178\}$

NIS: $\bar{A}=\{0.0045 ; 0.1186 ; 0.0181 ; 0.0453 ; 0.2309 ; 0.031850 ; 0.0005\}$

Table 9 Separation distance from PIS, NIS and relative closeness values

\begin{tabular}{|c|c|c|c|}
\hline Separation from negative alternative solution is & Separation from positive alternative solution is & $C c j$ & Experiments \\
\hline 0.237356 & 0.241261 & 0.495921 & 1 \\
\hline 0.240331 & 0.201935 & 0.543408 & 2 \\
\hline 0.257842 & 0.188596 & 0.577554 & 3 \\
\hline 0.236293 & 0.240705 & 0.495375 & 4 \\
\hline 0.239683 & 0.201571 & 0.543185 & 5 \\
\hline 0.258793 & 0.189618 & 0.577134 & 6 \\
\hline 0.25152 & 0.340012 & 0.425201 & 7 \\
\hline 0.261766 & 0.18006 & 0.592464 & 8 \\
\hline 0.28142 & 0.20734 & 0.575784 & 9 \\
\hline 0.24321 & 0.301308 & 0.446652 & 10 \\
\hline 0.237775 & 0.2463 & 0.491195 & 11 \\
\hline 0.319364 & 0.264838 & 0.546668 & 12 \\
\hline 0.239905 & 0.23553 & 0.504600 & 13 \\
\hline 0.243265 & 0.198792 & 0.550303 & 14 \\
\hline 0.258595 & 0.204672 & 0.558199 & 15 \\
\hline 0.240962 & 0.201818 & 0.544203 & 16 \\
\hline 0.238795 & 0.241321 & 0.497370 & 17 \\
\hline 0.319048 & 0.276327 & 0.535877 & 18 \\
\hline 0.250643 & 0.334188 & 0.428574 & 19 \\
\hline 0.265712 & 0.178394 & 0.598307 & 20 (Best Alternative) \\
\hline 0.280959 & 0.218676 & 0.562328 & 21 \\
\hline 0.250335 & 0.3333 & 0.428924 & 22 \\
\hline 0.265823 & 0.1785 & 0.598266 & 23 \\
\hline 0.281614 & 0.221117 & 0.560168 & 24 \\
\hline 0.246501 & 0.235997 & 0.510885 & 25 \\
\hline 0.239204 & 0.21014 & 0.532341 & 26 \\
\hline 0.25914 & 0.198252 & 0.566561 & 27 \\
\hline 0.245993 & 0.290575 & 0.458457 & 28 \\
\hline 0.23676 & 0.250539 & 0.485862 & 29 \\
\hline 0.320323 & 0.270627 & 0.542047 & 30 \\
\hline 0.252158 & 0.328422 & 0.434321 & 31 \\
\hline 0.259969 & 0.189967 & 0.577791 & 32 \\
\hline 0.281622 & 0.211778 & 0.570778 & 33 \\
\hline 0.245591 & 0.290996 & 0.457691 & 34 \\
\hline 0.238402 & 0.25232 & 0.485819 & 35 \\
\hline 0.319015 & 0.268233 & 0.543237 & 36 \\
\hline
\end{tabular}

By employing TOPSIS method, as explained above, the best solution obtained is experiment No.20 that corresponds to $D_{\mathrm{F}}$ - second oil, $T_{\text {on }}-40$ micro seconds, $I_{\mathrm{d}}$ 12 amps, $\zeta-11 \%, V_{\mathrm{g}}-40 \mathrm{~V}, T_{\mathrm{M}}-\mathrm{Cu}, T_{\mathrm{L}}-0.1 \mathrm{~s}$. This combination gives the values of $M R R$ and $S R$ as 4.8870 and 7.426 respectively.

\section{CONCLUSIONS}

This work presents the experimental investigations during EDM of Inconel 825. A total of seven parameters have been considered in this work. After analysis of experimental results, the following conclusions may be drawn:

1. Discharge current, tool electrode lifts time and tool materials have significant influence on the MRR. The most influencing factor is found to be discharge 
current with a contribution of $41.53 \%$ toward $M R R$ followed by tool electrode lift time and tool material. The higher parameter level of discharge current, tool electrode lift time and tool material are suggested for higher removal of material during EDM of Inconel 825 .

2. The tool material, pulse-on-time and discharge current showed significant contribution on TWR. To get the low $T W R$, these significant factors should have lower level values.

3. Pulse-on-time, discharge current and tool material have significant effect on the $S R$. To achieve the better surface finish on the machined surface, these significant factors should have lower level values.

4. SEM, EDXS and XRD have been carried out to find out the metallurgical changes, material transfer and the formation of compound formed after EDM process. SEM results from three electrode material showed the presence of overlapping craters with variation in sizes along with micro crack present throughout work piece. EDXS results revealed that major contribution is Carbon (C), Oxygen $\left(\mathrm{O}_{2}\right)$, Iron ( $\left.\mathrm{Fe}\right)$, Nickel (Ni), Chromium $(\mathrm{Cr})$ and little amount of Molybdenum (Mo) which is transferred to the surface of the work piece. XRD analysis revealed the compound formed as $\mathrm{Cr}_{12} \mathrm{Fe}_{22} \mathrm{MO}_{4} \mathrm{NbNi}_{10} \mathrm{Si}_{9}, \quad \mathrm{Cr}_{2} \mathrm{Fe}_{6.7} \mathrm{Mo}_{0.1} \mathrm{Ni}_{1.3} \mathrm{Si}_{0.3}$, $\mathrm{C}_{0.60} \mathrm{Cr}_{1.13} \mathrm{Fe}_{8.5} \mathrm{Mn}_{0.8} \mathrm{Mo}_{0.04} \mathrm{Nb}_{0.01} \mathrm{Ni}_{0.08} \mathrm{Si}_{0.7} \mathrm{~V}_{0.02}$.

5. TOPSIS method has been successfully employed as multi-objective optimization technique. By employing TOPSIS method, the optimal combination of input parameters has been obtained v.i.z. $D_{\mathrm{F}}$ - second oil, $T_{\mathrm{on}}$ - 40 micro seconds, $I_{\mathrm{d}}-12 \mathrm{amps}, \zeta-11 \%, V_{\mathrm{g}}-40 \mathrm{~V}$, $T_{\mathrm{M}}-\mathrm{Cu}, T_{\mathrm{L}}-0.1 \mathrm{~s}$.

\section{REFERENCES}

[1] Aytekin, H. \& Akcin, Y. (2013). Characterization of boridedIncoloy 825 alloy. Materials and Design, 50, 515521. https://doi.org/10.1016/j.matdes.2013.03.015

[2] Ezugwu, O. E. (2005). Key improvements in the machining of difficult-to-cut aerospace super alloys. International Journal of Machine Tools \& Manufacture, 45, 1353-1367. https://doi.org/10.1016/j.jimachtools.2005.02.003

[3] Kunieda, M., Yoshida, M., \& Tanighu. N. (1997). Electrical Discharge Machining in Gas. CIRP Annals - Manufacturing Technology, 46, 143-146. https://doi.org/10.1016/S0007-8506(07)60794-X

[4] Tahir, W., Jahanzaib, M., \& Raza, A. (2019). Effect of process parameters on cutting speed of wire EDM process in machining HSLA steel with cryogenic treated brass wire. Advances in Production Engineering \& Management, 14(2), 143-152. https://doi.org/10.14743/apem2019.2.317

[5] Bharti, P. S., Maheshwari, S., \& Sharma, C. (2010). Experimental investigation of Inconel 718 during diesinking electric discharge machining. International Journal of Engineering Science and Technology, 2(11), 6464-6473.

[6] Shen, Y., Liu, Y., Zhang, Y., Dong, H., Sun, P., \& Wang, X. (2016). Effects of an electrode material on a novel compound machining of Inconel 718. Materials and Manufacturing Processes, 31, 845-851. https://doi.org/10.1080/10426914.2015.1019133

[7] Kumar, A., Maheshwari, S., Sharma, C., \& Beri, N. (2011). Analysis of machining characteristics in additive mixed Electric Discharge Machining of nickel-based super alloy Inconel 718. Materials and Manufacturing Processes, 26 , 1011-1018. https://doi.org/10.1080/10426914.2010.527415
[8] Singh, A. K., Kumar, S., \& Singh, V. P. (2014). Optimization of parameters using conductive powder in dielectric for EDM of super co605 with multiple quality characteristics. Materials and Manufacturing Processes. https://doi.org/10.1080/10426914.2013.864397

[9] Yadav, U. S. \& Yadava, V. (2014). Parametric study on electrical discharge drilling of aerospace nickel alloy. Materials and Manufacturing Process, 29, 260-266. https://doi.org/10.1080/10426914.2013.864406

[10] Durairaj, M., Ansari, A. K. S., \& Gauthamkumar, M. H. (2013). Parametric optimization of wire cut electrical discharge machining. International Journal of Engineering \& Technology, 3(2), 212-215. https://doi.org/10.14419/ijet.v3i2.1807

[11] Singh, S. \& Pandey, A. (2013). Some studies into electrical discharge machining of nimonic 75 super alloy using rotary copper disk electrode. Journal of Materials Engineering and Performance, 22, 1290-1303. https://doi.org/10.1007/s11665-012-0412-z

[12] Kumar, P., Mathan, K., Sivakumar, \& Jayakumar, N. (2017). Multi-objective optimization and analysis of coppertitanium diboride electrode in EDM of monel $400^{\mathrm{TM}}$ alloy. Materials and Manufacturing Processes https://doi.org/10.1080/10426914.2017.1415439

[13] Guo, C., Di, S., \& Wei, D. (2015). Study of electrical discharge machining performance in water-based working fluid. Materials and Manufacturing Processes, 31, 18651871. https://doi.org/10.1080/10426914.2015.1127946

[14] Rahul, Dutta, S., Biswal, B. B., \& Mahapatra, S. S. (2017). Electrical discharge machining of Inconel 825 using cryogenically treated copper electrode: emphasis on surface integrity and metallurgical characteristics. Journal of Manufacturing Processes, 26, 188-202. https://doi.org/10.1016/j.jmapro.2017.02.020

[15] Kumar, A., Mandal, A., Dixit, A. R., \& Das, A. K. (2017). Performance evaluation of $\mathrm{AL}_{2} \mathrm{O}_{3}$ nano powder mixed dielectric for electric discharge machining of Inconel 825. Materials and Manufacturing Processes. https://doi.org/10.1080/10426914.2017.1376081

[16] Mohanty, A., Talla, G., \& Gangopadhyay, S. (2014). Experimental investigation and analysis of EDM characteristics of Inconel 825. Materials and Manufacturing Processes, 29, 540-549. https://doi.org/10.1080/10426914.2014.901536

[17] Prabhu, S. \& Vinayagam, B. K. (2011). AFM surface investigation of Inconel 825 with multi wall carbon nano tube in electrical dischargemachining process using Taguchi analysis. Archives of Civil and Mechanical Engineering, 11, 149-170. https://doi.org/10.1016/S1644-9665(12)60180-0

[18] Prabhu, S. \& Vinayagam, B. K. (2013). AFM nano analysis of Inconel 825 with single wall carbon nano tube in die sinking EDM process using Taguchi analysis. Arabian Journal of Science and Engineering, 38, 1599-1613. https://doi.org/10.1007/s13369-012-0348-5

[19] Deb, K., Pratap, A., Agarwal, S., \& Meyarivan, T. (2002). A fast and elastic multi-objective genetic algorithm: NSGA-II. IEEE transactions of Evolutionary Computation, 6(2), 182197. https://doi.org/10.1109/4235.996017

[20] Mandal, D., Pal, S. K., \& Saha, P. (2007). Modelling of electric discharge machining process using back propagation neural network and multi-objective optimization using nondominating sorting genetic algorithm-II. Journal of Material Processing Technology, 186, 154-162. https://doi.org/10.1016/j.jmatprotec.2006.12.030

[21] Somashekhar, K. P., Mathew, J., \& Ramachandaran, R. (2012). A feasibility approach by simulated annealing on optimization of micro-wire electric discharge machining parameters. International Journal of Advanced Manufacturing Technology, 61, 1209-1213. https://doi.org/10.1007/s00170-012-4096-1 
[22] Bagherian A. R. \& Teimouri R. (2017). Applications of Taguchi, ANFIS and grey relational analysis for studying, modeling and optimization of wire EDM process while using gaseous media. International Journal of Advanced Manufacturing Technology, 88, 3527. https://doi.org/10.1007/s00170-016-9153-8

[23] Tang, L. \& Du, Y. T. (2014). Multi-Objective Optimization of Green Electrical Discharge Machining Ti-6Al-4V in Tap Water via Grey-Taguchi Method. Materials and Manufacturing Processes, 29, 507-513. https://doi.org/10.1080/10426914.2013.840913

[24] Prabhu, S. \& Vinayagam, B. K. (2016). Multiresponse optimization of EDM process with nanofluids using TOPSIS method and genetic algorithm. Archives of Mechanical Engineering, LXIII, 45-71. https://doi.org/10.1515/meceng-2016-0003

[25] Juhr, S. H. (2004). Improved cemented carbide properties after Wire EDM by pulse shaping. Journal of Material Processing Technology, 149, 178-183. https://doi.org/10.1016/j.jmatprotec.2004.02.037

[26] Khatter, C. P. (2009). Analysis of surface integrity in Electrical discharge machining process for Tungsten Carbide material, Thapar University. https://doi.org/10.1179/175158308X383198

[27] Talla, G., Gangopadhyay, S., \& Biswas, C. K. (2016). Influence of graphite powder mixed EDM on the surface integrity characteristics of Inconel 625. Particulate Science and Technology. https://doi.org/10.1080/02726351.2016.1150371

[28] Wagle, S., Kaneno, Y., Nishimura, R., \& Takasugi, T. (2013). Evaluation of the wear properties of dual two-phase Ni3Al/Ni3V intermetallic alloys. Tribology International, 66, 234-240. https://doi.org/10.1016/j.triboint.2013.05.016

[29] Hwang, C. L. \& Yoon, K. (1981). Multiple Attribute Decision Making: Methods and Application, SpringerVerlag, New York. https://doi.org/10.1007/978-3-642-48318-9_3

\section{Contact information}

Himanshu PAYAL, Assistant Professo Department of Mechanical Engineering Sharda University, Greater Noida, India E-mail: himanshupayal@rediffmail.com

Pushpendra S. BHARTI, Associate Professor (Corresponding author)

University School of Information, Communication \& Technology,

Guru Gobind Singh Indraprastha University,

Sector 16 C, New Delhi-110078, India

E-mail: psbharti@ipu.ac.in

\section{Sachin MAHESHWARI, Professor}

Manufacturing Process and Automation Engineering Division,

NetajiSubhash Institute of Technology,

Sector -3, Dwarka, New Delhi-110078, India

E-mail: ssaacchhiin@gmail.com

Divya AGARWAL, Research Scholar

University School of Information, Communication \& Technology,

Guru Gobind Singh Indraprastha University,

Sector 16 C, New Delhi-110078, India

E-mail: er.divya7i@gmail.com 